\title{
Enlightening cyclists: an evaluation study of a bicycle light communication system aimed to support older cyclists in traffic interactions
}

\section{Frank Westerhuis*}

Faculty of Behavioural and Social Sciences,

University of Groningen,

Grote Kruisstraat 2/1, 9712 TS,

Groningen, The Netherlands

Email: f.westerhuis@rug.nl

*Corresponding author

\section{Carola Engbers, Rosemary Dubbeldam and Hans Rietman}

\author{
Roessingh Research and Development, \\ Roessinghsbleekweg 33b, $7522 \mathrm{AH}$, \\ Enschede, The Netherlands \\ and \\ Faculty of Engineering Technology, \\ Department of Biomechanical Engineering, \\ University of Twente, \\ P.O. Box 217, 7500 AE, \\ Enschede, The Netherlands \\ Email: engbersc@gmail.com \\ Email: r.dubbeldam@uni-muenster.de \\ Email: j.s.rietman@rrd.nl
}

\section{Dick de Waard}

Faculty of Behavioural and Social Sciences, University of Groningen, Grote Kruisstraat 2/1, 9712 TS, Groningen, The Netherlands

Email: d.de.waard@rug.nl

\begin{abstract}
In the Netherlands, older cyclists run an increased risk of bicycle crashes. Critical factors are low-speed interactions, stopping, (dis)mounting, and potentially misjudging riding speeds. A Bicycle Light Communication System (BLCS) was therefore developed that displayed riding speed, braking, and turning intentions. In an experiment, 21 older and 20 younger cyclists observed BLCS-signals of a lead cyclist and estimated speeds of an approaching cyclist, with and without BLCS. Interviews were conducted to assess general opinions on BLCS and its influence on cycling behaviour.
\end{abstract}


In a small follow-up study, twelve older cyclists used a BLCS-bicycle one week to explore first user-impressions. The majority evaluated the BLCS positively, mainly the turning indicator and brake light components, even though interpreting the speed signals was difficult. Although the first userimpressions revealed that the direction indicator does not influence selfreported balance (positively or negatively), the majority reported that they would like to use a BLCS themselves.

Keywords: cycling; ageing; safety; intention; interaction; communication; support; interpretation; acceptance; mental workload.

Reference to this paper should be made as follows: Westerhuis, F., Engbers, C., Dubbeldam, R., Rietman, H. and de Waard, D. (2021) 'Enlightening cyclists: an evaluation study of a bicycle light communication system aimed to support older cyclists in traffic interactions', Int. J. Human Factors and Ergonomics, Vol. 8, No. 3, pp.294-317.

Biographical notes: Frank Westerhuis is a $\mathrm{PhD}$ student at the University of Groningen. After receiving his MSc degree in Clinical Neuropsychology in 2013, he started working as a researcher at the Department of Clinical and Developmental Neuropsychology at the University of Groningen. His main focus is on traffic psychology, mainly of older cyclists and their experiences in the cycling infrastructure. As a researcher he contributed to the Forgiving Cycle Path project, aimed at improving the current Dutch cycling infrastructure to increase the safety for older cyclists. He became a $\mathrm{PhD}$ student at the same university and expanded his area of research to traffic interactions of older cyclists with other road users in 2015 .

Carola Engbers received her Bachelor's in Psychology in Enschede and graduated in Psychology in Groningen in 2012. She began working at Roessingh Research and Development in 2012 as a PhD student, which is about supporting the older cyclists in traffic. The data eventually formed the basis for her PhD thesis (Twente University, 2019).

Rosemary Dubbeldam graduated from Delft University (MSc in Aerospace Engineering, 1996) and worked at Delphi Automotive Systems in Wuppertal, Germany, developing airbags for the automotive industry and lower extremity computer models (1997-2003). She started as (part-time) Researcher at Roessingh Research and Development in 2015 where she performed her PhD thesis (Twente University, 2012) and worked as Senior Research Engineer on projects including measurements and analysis of foot and ankle motion of patients; biomechanics of bicycle and cyclist; and the development of technological support for cyclists. She works as a post-doc and lecturer at the Sport Institute of the Westfälische Wilhelms University in Münster, Germany since 2018. Furthermore, as a physiotherapist (THIM University, 2007), she treats patients with foot and ankle problems.

Hans Rietman is a Physiatrist and Professor in Rehabilitation Medicine and Technology at the University of Twente. He performs his clinical work at Roessingh Centre for Rehabilitation. He is also appointed at the research institute Roessingh Research and Development and an Adjunct Professor at Northwestern University, Chicago, USA. His research focuses on the clinical use of technology in restoration of functions in patients with neurological disorders and patients with amputations of upper and lower extremities. He is a co-editor of the Dutch book of rehabilitation medicine for adults and the Dutch book of amputation and prosthetics of the lower extremities and (co)author of more than 100 PubMed cited papers. 
Dick de Waard is a Professor of Traffic Psychology and the Retention of Mobility in the Department of Psychology at the University of Groningen. He received his $\mathrm{PhD}$ in Psychology from the University of Groningen in 1996.

\section{Introduction}

In the Netherlands, cycling is a common mode of transportation and many people use the bicycle daily (Harms and Kansen, 2018). Cycling contributes positively to health, social participation, and quality of life (De Hartog et al., 2010; Fishman et al., 2015; Oja et al., 2011) and it is important that people keep cycling safely for as long as they wish (Tour de Force, 2017). A specific group that is currently of interest due to safety concerns, however, is older cyclists (Ministry of Transport, Public Works, and Water Management, 2008; Rijkswaterstaat, 2016). Since more older cyclists have continued to cycle over the recent years, their share in traffic has substantially increased (Kennisinstituut voor Mobiliteitsbeleid, 2017; Schepers et al., 2017). This development is positive for healthy ageing as cycling benefits physical fitness (Ryan et al., 2016) and increases the life space area of older people (Van Cauwenberg et al., 2019). However, age-related cognitive and physical decline are related to an increased risk of falling from the bicycle (Engbers et al., 2018a). Indeed, it is estimated that a large proportion of bicycle crashes in the Netherlands concern older cyclists (Schepers et al., 2017) and this group is susceptible to sustain severe injuries after a bicycle crash (OECD, 2001; SWOV, 2013). Even though the majority of these crashes are single-bicycle crashes (Schepers, 2013; Schepers et al., 2015), interactions with other road users are an important factor as well (Ormel et al., 2008; Westerhuis and De Waard, 2016; Boele-Vos et al., 2017; VeiligheidNL/Rijkswaterstaat, 2017). Several initiatives have therefore been started to investigate possibilities to support older cyclists with their interactions with other road users.

\subsection{Keeping balance}

One explanation for the risk of falling of older cyclists is that ageing may be accompanied by problems with motor coordination and balance (SWOV, 2013; VeiligheidNL/Rijkswaterstaat, 2017). For example, Ormel et al. (2008) found that in the Netherlands, approximately one quarter of bicycle crashes that required hospitalisation of cyclists $\geq 55$ years in 2008 occurred while mounting or dismounting the bicycle, and more recent studies show similar results (Hagemeister and Tegen-Klebingat, 2012; Kruijer et al., 2012; Scheiman et al., 2010; VeiligheidNL/Rijkswaterstaat, 2017). Contributing factors are that older cyclists not only mount and dismount a bicycle differently than younger cyclists (Dubbeldam et al., 2017b), but also may have difficulties recovering from balance disturbances while riding at low speeds (Bulsink et al., 2016). Because interactions with other road users, such as giving priority or responding to actions of other road users, typically require cyclists to decrease speed or to stop and dismount the bicycle, such interactions are critical in bicycle crashes of older cyclists (Boele-Vos et al., 2017; Davidse et al., 2014a, 2014b). These crashes may therefore be prevented by supporting older cyclists during similar interactions. 
Other safety-related interactions that may impact balance are looking over the shoulder and indicating direction (Johnsen and Funk, 2019). Every cyclist frequently has to look over the shoulder to monitor traffic from behind. This is particularly necessary before turning left (in right-hand traffic countries) and it is known that older cyclists find this a difficult manoeuvre to perform safely (Bernhoft and Carstensen, 2008). Instead, some choose to cross an intersection on foot even though this requires them to dismount their bicycle. Shortly before turning, one hand has to be taken off the handlebars to point into the intended direction. This gesture forces the rider to balance the bicycle with only one hand and is currently the only and official way for cyclists to indicate direction understandably (Walker, 2005). Even though some intentions might be derived from other observable cycling behaviours (Hemeren et al., 2014), not stretching an arm impairs other cyclists in predicting turning intentions, showing that it is indeed a crucial gesture (Westerhuis and De Waard, 2017). As balance problems are common in older cyclists, looking over the shoulder and indicating direction could increase their risk on falling. It may therefore be beneficial to provide older cyclists with alternative options for detecting traffic from behind as well as for indicating direction.

\subsection{Cycling speed}

Thanks to the electric bicycle, but also because of improved bicycle designs in general, more older people cycle (Schepers et al., 2014). Compared to conventional bicycles, (older) cyclists may ride more frequently and further distances on electric bicycles because less physical effort is required to ride comfortably (Theurel et al., 2012). Less physically fit people may therefore still be able to ride an electric bicycle if riding a conventional bicycle is not possible anymore (Johnson and Rose, 2015). Although cyclists tend to ride faster on an electric bicycle if they are physically capable of riding both an electric and a conventional bicycle, it seems that the riding speed of older ecyclists is more comparable to the riding speed of younger cyclists, regardless of bicycle type (Vlakveld et al., 2015). Indeed, naturalistic cycling studies with older participants riding their own bicycles show no or small speed differences between electric and conventional bicycle riders, suggesting that some older people may use an electric bicycle to reach 'conventional' riding speeds (Schleinitz et al., 2017; Westerhuis and De Waard, 2016). This could mean that electric bicycles support older cyclists with keeping balance mainly because it is easier to ride and stabilise a bicycle at higher speeds and that gaining sufficient speed from a standstill might be performed more stable as well (Kooiman et al., 2011; Twisk et al., 2017). Higher speeds, however, also require faster reaction times to be able to avoid a crash during critical situations or interactions in traffic. As the process of ageing is accompanied by slower reaction times (OECD, 2001) and higher speeds generally increase the risk and severity of crashes (Wegman et al., 2006), older people may be particularly at risk for serious crashes if they attain increased speeds without increasing their distances (safety margins) towards other road users, for example (Näätänen and Summala, 1976, cited in Kulmala and Rämä, 2013).

\subsection{Speed perception}

In order to have sufficient safety margins, not only older cyclists, but every road user in general should receive sufficient 'time and space' from other road users as well. For this reason, it is essential that all road users are able to perceive each other's speed and 
distance. During daylight, drivers use visual cues such as (changes in) the angular size of the back of a vehicle and (changes in) the observable size of the road ahead to estimate distance and closure rates to lead vehicles (Moore and Rumar, 1999). At night and without street lights, these cues are much less visible and road users therefore rely on rear lights, in particular (changes in) brightness, visual angle, and/or visual space between lights (Parker et al., 1964, cited in Moore and Rumar, 1999). For cyclists specifically, other road users also use a cyclist's cadence (i.e., pedal rotation frequency) as a visual cue to estimate riding speed (Schleinitz et al., 2016). With more recent (electric) bicycle designs, however, it is not necessary to pedal with high cadence to reach comfortable speeds anymore. Furthermore, from well-trained (sport) cyclists, it is known that particularly older cyclists benefit from lower cadences and apply this pedalling strategy more frequently than younger cyclists (Sacchetti et al., 2010). Even though racing cyclists also tend to ride at high speeds with relatively low cadences, they are clearly recognisable as fast riders based on their appearance (e.g., posture, clothing, and bicycle design). E-cyclists, for example, are becoming increasingly difficult to recognise as the design of electric bicycles is similar to conventional bicycles (Dozza et al., 2016). Therefore, other road users are at times surprised by the speed at which (older) e-cyclists approach them because low cadence generally indicates low effort and, as a result, a low riding speed (Haustein and Møller, 2016; Schleinitz et al., 2016). In turn, this may lead to underestimating the speed of e-bicycle riders (Petzoldt et al., 2017b). Particularly at locations where people are under time pressure to make decisions (e.g., intersections), it is important that the speed of all types of road users, including older e-cyclists, are estimated as close as possible to their true speeds because this enables road users to maintain adequate safety margins and choose safer (larger) gaps (Dozza et al., 2016; Petzoldt et al., 2017a).

\subsection{On-bicycle solutions}

With regard to displaying explicit information about speed and turning intentions, safe and successful solutions so far have been the norm for other forms of (motorised) transport for decades: brake lights and turning indicators (Moore and Rumar, 1999). Even though most vehicle brake lights were originally developed for use in darkness, more recent designs, including centre high mounted stop lights, have shown to reduce driver reaction times and (rear-end) crash risk during daylight as well (see e.g., Kahane and Hertz, 1998; Moore and Rumar, 1999; Green, 2000). As for turning indicators, there is little doubt that these benefit safety because signalling enables car drivers to anticipate turning manoeuvres of lead vehicles, resulting in safer following behaviour (Muhrer and Vollrath, 2010) as well as reduced crash risk (Sullivan and Flannagan, 2012). In a similar way, it should be possible to implement similar brake and turn signals on bicycles. Apart from informing other road users, a turn signalling system could also improve balance as the operation does not require releasing one hand from the handlebars. Also other onbicycle solutions aimed at supporting older cyclists have been developed and tested. For example, difficulties with mounting and dismounting may be alleviated by adjusting the geometry of a bicycle and/or providing a saddle that automatically lowers its position while riding at lower speeds (Dubbeldam et al., 2017a). Furthermore, rear-view detection systems may assist older cyclists to detect traffic from behind (Engbers et al., 2016; Engbers et al., 2018b). 


\subsection{Bicycle Light Communication System}

A Bicycle Light Communication System (BLCS) was developed to provide an alternative means for cyclists to show turning intentions and riding speed to other road users. This BLCS contained a turn indicator, speed indicator, and a brake light, all integrated in a front and a rear bicycle light unit. The system's main aim was to not only provide other road users with explicit light signals about turning intentions and riding speed, but also about acceleration, deceleration, and braking. By using explicit light signals, it was hypothesised that the speed of the rider could be estimated more accurately than on the basis of observable rider behaviour alone. Furthermore, it should no longer be necessary to signal with the arm, thus both hands can remain on the handlebars while turning. This should not only benefit keeping balance, but also enable other road users to anticipate a cyclist's turning intentions and adjust safety margins accordingly.

\subsection{Research aim}

The first and primary objective of this study was to explore how (naïve) older and younger cyclists experience and interpret light signals shown by a BLCS. For this reason, an on-site experiment was conducted in which older and younger participants were invited to cycle together with a researcher that used a BLCS on the bicycle (Study 1). Hereafter, a small group of older cyclists was invited to use a BLCS-instrumented bicycle for themselves to get first-hand experience as a BLCS-user, particularly with regard to the direction indicator and its perceived effects on keeping balance (Study 2).

\section{Materials and methods}

In Study 1, effects of observing BLCS-signals on cycling behaviour were investigated and subjective opinions regarding visibility, interpretation, intention to use, mental effort, expected safety enhancement, and acceptance were collected. In Study 2, a small followup was performed with older cyclists using a BLCS-bicycle for their personal cycling activities during one week. Both studies were approved by the University of Groningen Psychology Ethics Committee (16414-O and 16415-O).

\subsection{Study 1}

\subsubsection{Participants}

As older cyclists are expected to benefit most from a BLCS, participants $\geq 60$ years and capable of cycling independently were recruited. Younger cyclists $(\leq 35$ years) were also recruited because in particular communication between older and younger cyclists tends to be difficult (Ryan et al., 2016). Older cyclists were recruited by distributing flyers in local shops and community centres in the city of Groningen. For younger participants, flyers were distributed in the main buildings of the University of Groningen and on Facebook groups with people from Groningen. All participants received a $€ 15$ voucher for participation. 
Twenty-one older and twenty younger cyclists participated in Study 1 (see Table 1). The majority lived in Groningen and brought their own bicycle. Two (younger) participants used a bicycle provided by the researchers.

Table 1 Demographical participant data of Study 1

\begin{tabular}{lccccccc}
\hline \multirow{2}{*}{ Group } & \multicolumn{2}{c}{ Age } & Gender & \multicolumn{3}{c}{ Living environment* } & \multirow{2}{*}{$n$} \\
\cline { 2 - 6 } & $M$ & S.D. & \% Male & \% Urban & \% Village & \% Rural nn & \\
\hline Younger & 25.5 & 3.9 & 40.0 & 90.0 & 5.0 & 5.0 & 20 \\
Older & 69.7 & 5.3 & 66.7 & 85.7 & 9.5 & 0.0 & 21 \\
Total & 48.1 & 22.9 & 53.7 & 87.8 & 7.3 & 2.4 & 41 \\
\hline
\end{tabular}

Note: * One participant did not provide any information concerning his or her living environment.

\subsubsection{The instrumented BLCS-bicycle}

A bicycle (Gazelle Miss Grace, ladies' model, seven gears, $54 \mathrm{~cm}$ frame size) was instrumented with a BLCS that, apart from the main bicycle light in the centre of the unit, displayed several aspects of rider behaviour and intention (see Figures 1 and 2). The light signals were shown by LEDs bundled in circles and triangles (arrows) on two units that were mounted as the front and rear bicycle lights. Different signals showed turning intentions (i.e., a turning indicator), braking, riding speed, or a flash-signal to draw the attention of other road users. The speed and brake signals were automatically controlled by a CPU located in a small bag below the handlebars. The cyclist controlled the turning indicator and the attention-signal with a small remote-controller located on the left-hand side of the handlebars (Figure 3).

Figure 1 From left to right: the BLCS front unit, BLCS rear unit, and a close-up photo of the BLCS rear unit (see online version for colours)
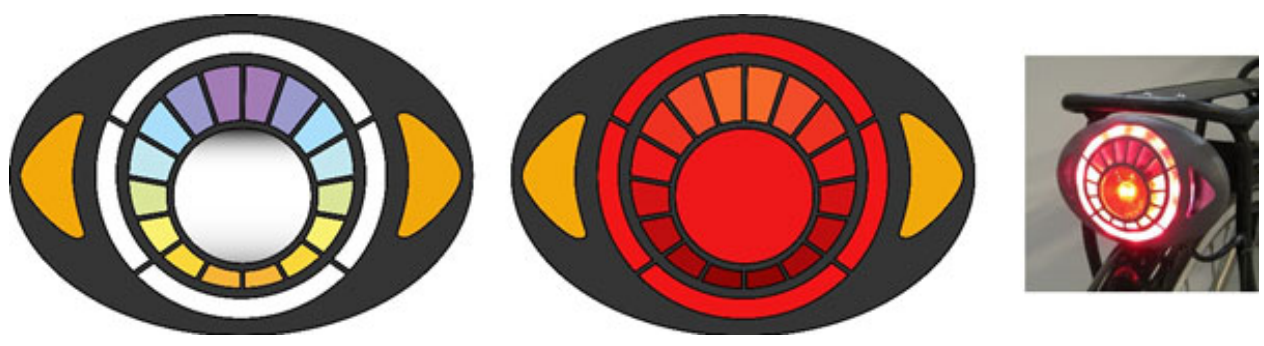

The turning indicators were not only located on the far-most left and right sides of the front and rear BLCS-units, but also in the grips of the handlebars (see Figures 1 and 2). The indicators on the BLCS had amber-coloured LEDs in the shape of an arrow pointing in the intended direction. The indicators in the grips of the handlebars contained amber LEDs only. When enabled, the LEDs blinked similarly to indicators on cars and motorcycles and were disabled automatically after a turn was completed. 
The BLCS also had a speed indicator which displayed the riding speed using graphical intervals. This feature had the visual shape of a ring located around the main bicycle light (see Figure 4). The speed indicators had yellow-to-white-coloured and darkto-light-red-coloured LED-rings on the front and rear units, respectively. The system continuously measured riding speed and conveyed this speed by lighting up (a selection of) LEDs in an upward direction as the cyclist reached higher speeds (Figure 4). The idea behind this is that it would be recognisable, as with a dynamo the headlight would light up brighter with increasing speed.

Figure 2 The instrumented BLCS-bicycle with activated indicators (see online version for colours)

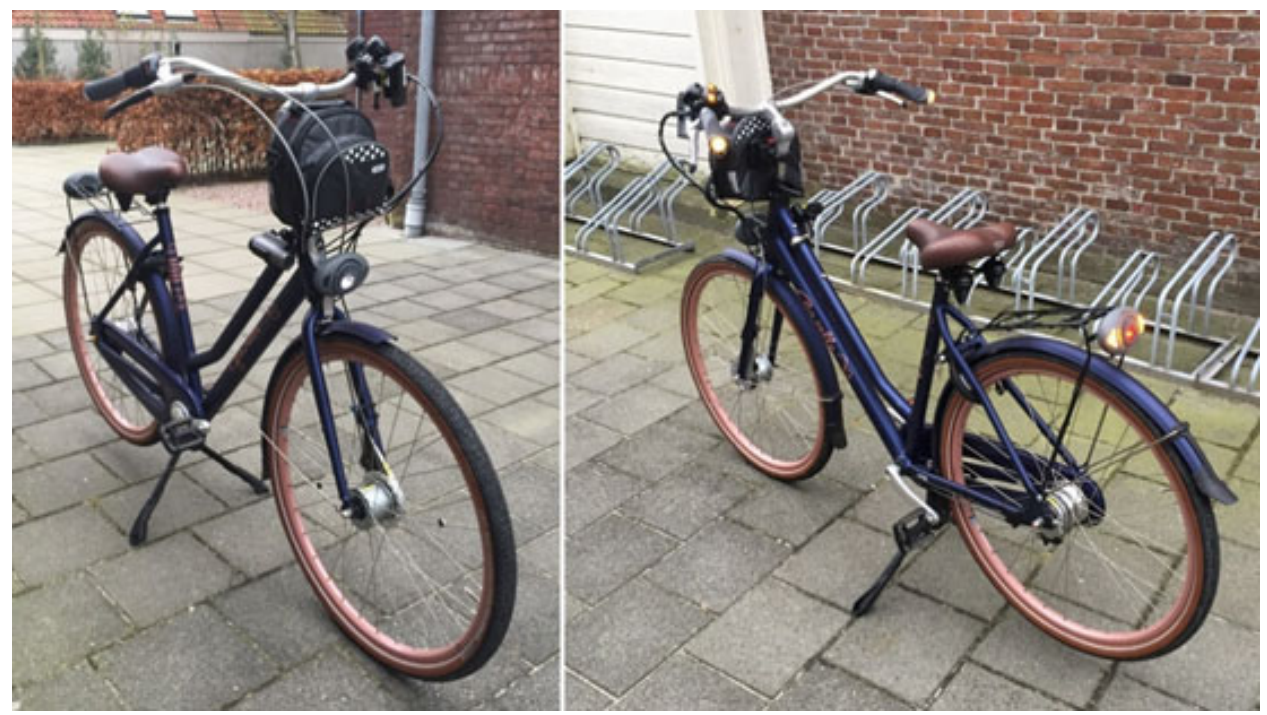

Figure 3 The BLCS remote-controller (see online version for colours)

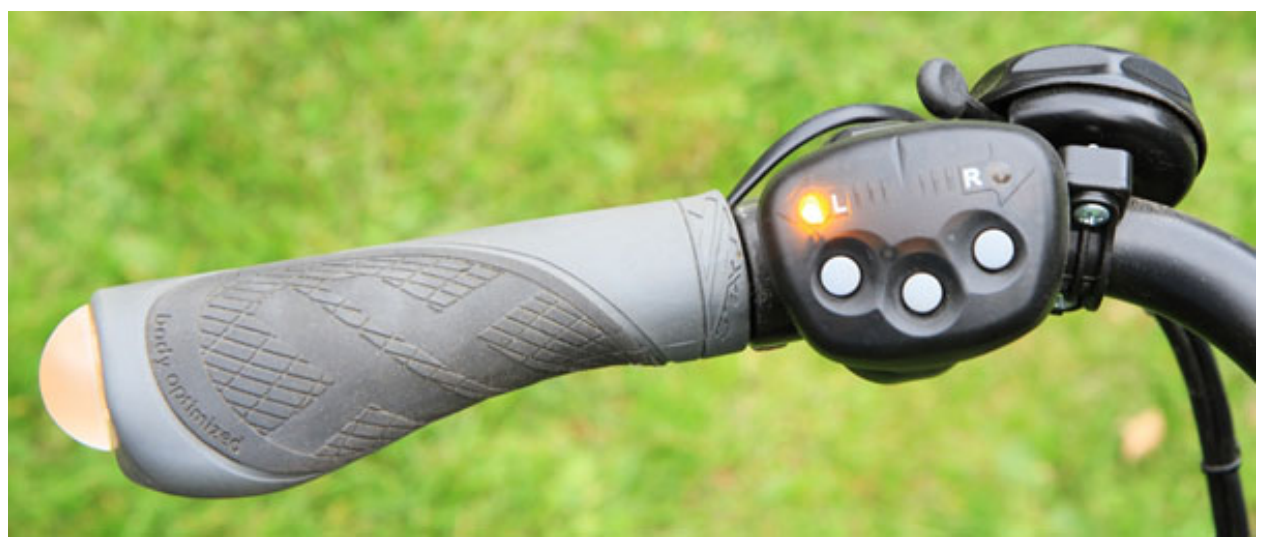


Figure 4 The light signals that displayed cycling speed (see online version for colours)

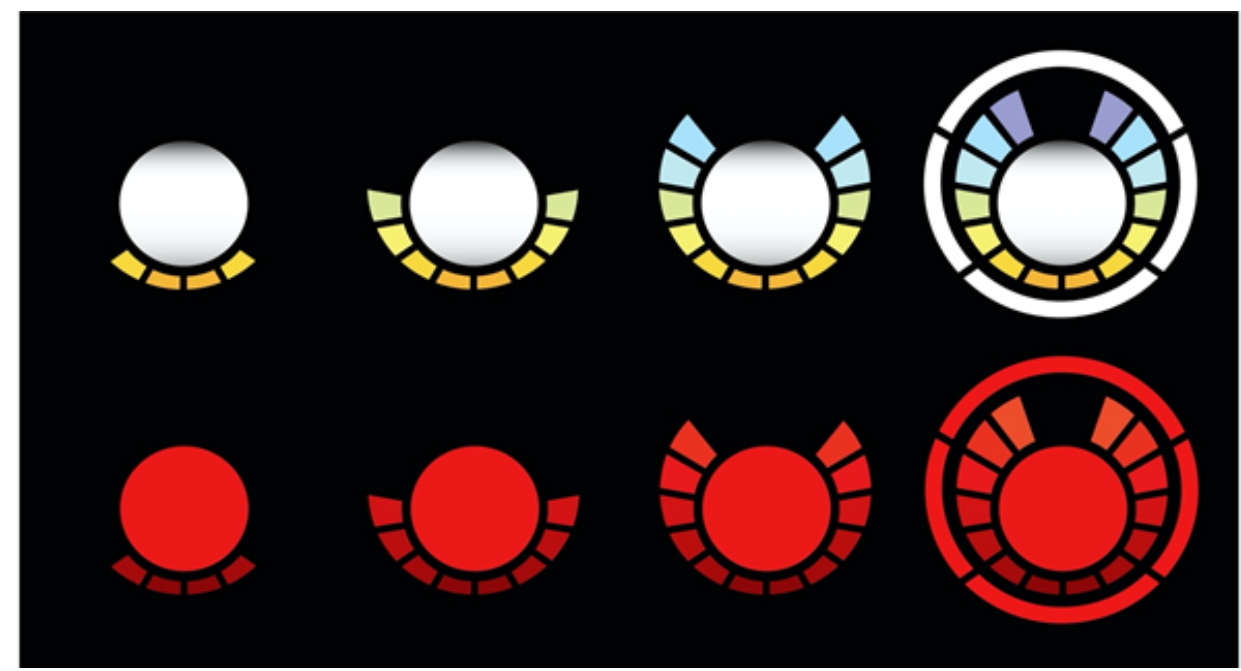

Notes: From left to right: very slow $( \pm 7 \mathrm{~km} / \mathrm{h})$, slow $( \pm 11-12 \mathrm{~km} / \mathrm{h})$, medium

$( \pm 17-18 \mathrm{~km} / \mathrm{h})$, and fast $( \pm 21-22 \mathrm{~km} / \mathrm{h})$, with at the right the attention or brake light for the front (upper pictures) and rear (lower pictures) bicycle lights, respectively.

The last features of the BLCS were the attention and brake signals on the front and rear units, respectively. The attention-signal was incorporated in the front BLCS-unit as a white-lighted outer-ring placed between the speed and direction signals (Figure 4, upperright picture) and could be activated with the remote-controller. On the rear BLCS-unit, a brake light was installed at the same location (Figure 4, lower-right picture). The brake light was automatically activated when the accelerometer exceeded a deceleration threshold of $1 \mathrm{~m} / \mathrm{s}^{2}$.

Figure 5 A schematic representation of the cycle paths in the experiment (see online version for colours)

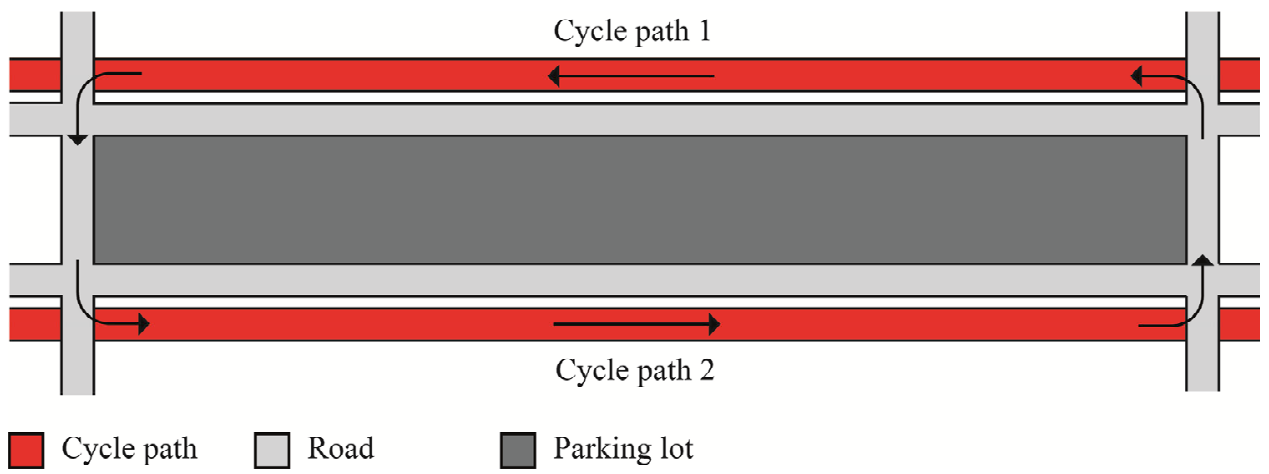

Notes: The measurements were only performed on the two cycle paths (red).

The road in-between the paths was used to cycle from one path to the other. 


\subsubsection{Location}

To demonstrate the signals of the BLCS, two researchers rode a BLCS-bicycle at a quiet location in the city of Groningen. At this location, there were two separate one-way cycle paths, in reverse directions, surrounding a parking lot (see Figure 5). Both paths were approximately 170 metres long and 2.3 metres wide. The paths were used in succession: a small 'circuit' was created by crossing the road.

\subsubsection{Cameras}

Cycling behaviour was recorded with three Contour $+2^{\mathrm{TM}}$ digital action cameras with GPS. Two were mounted on the BLCS-bicycle and one on the participant's bicycle. On the BLCS-bicycle, one camera was directed forward and one to the side for the researchers to review the rides from 'their' point of view later. A third camera was mounted on the handlebars of the participant's bicycle and this camera was directed forward to record the BLCS-bicycle ahead of the participant.

\subsubsection{Questionnaires}

Subjective information regarding visibility, signal interpretation, intention to use, and expected safety enhancement was gathered by means of a semi-structured interview. Furthermore, the acceptance of the system was assessed using a brief acceptance scale (Van der Laan et al., 1997) after demonstrating the front and rear bicycle lights. This scale was used to obtain an indication of the (expected) usefulness and satisfaction of the BLCS as a complete system and end product. Basically, these ratings provide insights in the probability that the target group (in this case older cyclists) would also be interested in using a BLCS. Mental effort was measured with the Rating Scale Mental Effort (RSME; Zijlstra, 1993) to assess whether the BLCS signals would lead to additional workload when assisting cyclists with a relatively basic, automatic task: keeping distance from a cyclist ahead.

\subsubsection{Procedure}

Before the experiment, participants received a letter with a general description of the study and an invitation to bring their own bicycle. If the latter was not possible, a conventional bicycle was offered to use instead. If participants had an electric bicycle (pedelec), they were asked to disable the electric support. At the experiment, the main goal of the research and the test procedure were explained. The BLCS-bicycle was shown to the participants and a researcher demonstrated all components. The speed indicator was demonstrated by rotating the BLCS-bicycle's front wheel while showing the lights. The participants were told that more lights corresponded to an increase in cycling speed. Hereafter, the participants could try the controller for the direction indicator. Remaining questions were answered and participants signed an informed consent form.

\subsubsection{Task 1: Following the researcher riding the BLCS-bicycle}

After the introduction, the participants mounted their own bicycle and followed the test leader who rode the BLCS-bicycle (Task 1). Participants with a bicycle speedometer were asked to disable it or to cover the display. Further instructions were limited: 'please 
follow the test leader, cycle as you usually do, and maintain a following-distance that feels comfortable'. Participants were also told to adhere to the traffic rules and to give priority whenever necessary.

Task 1 was divided into two conditions: the 'BLCS ON' and 'BLCS OFF' conditions. In the 'ON' condition, all BLCS-functions were active and participants could observe BLCS-information about riding speed, turning intentions, and braking of the BLCSbicycle rider. The 'OFF' condition was the control condition in which the BLCS was disabled as if it were a conventional bicycle. After both conditions, participants were asked to rate the amount of invested mental effort to estimate the speed required for comfortably following the test leader. This was performed with the RSME (Zijlstra, 1993). The order of presentation of the conditions was counterbalanced. Within each condition, four riding speed scenarios were randomly presented: the 'Slow', 'Accelerating', 'Fast', and 'Decelerating' scenarios (see Table 2 for details). Only at the end of the 'Accelerating' and 'Fast' scenarios, the brake light was also presented because in the 'Slow' and 'Decelerating' scenarios the speed was too low to reach the activation threshold before coming to a standstill.

Table 2 An overview of the speeds (in $\mathrm{km} / \mathrm{h}$ ) in each scenario

\begin{tabular}{lccc}
\hline Scenario & Starting speed & Ending speed & Brake light \\
\hline 'Slow' & 13 & 13 & No \\
'Accelerating' & 13 & 21 & Yes \\
'Fast' & 21 & 21 & Yes \\
'Decelerating' & 21 & 13 & No \\
\hline
\end{tabular}

\subsubsection{Task 2: Estimating the speed of the BLCS- bicycle}

After Task 1, the participant was asked to stand at a fixed location next to the cycle path. While standing, one of the researchers riding a BLCS-bicycle approached the participant from 60 metres and the participant was asked to estimate the researcher's riding speed in $\mathrm{km} / \mathrm{h}$ (Task 2). These estimations were performed six times: three times while the BLCS was enabled ('BLCS ON') and three times while it was disabled ('BLCS OFF'). Per condition, three speed scenarios were randomly presented: 'Slow' (11-12 km/h, gear 3), 'Medium' (17-18 km/h, gear 5), and 'Fast' (21-22 km/h, gear 7). The researchers used different gears per scenario to ensure that the pedal rotation frequency (cadence) remained as constant as possible. The participant could answer at any moment he or she preferred.

\subsubsection{Semi-structured interviews}

After Task 2, a concluding interview with open-ended questions was conducted in which participants were asked to give their overall opinion about the BLCS. Discussed topics were visibility, interpretation, expected safety enhancement, and possible intention of using or buying a BLCS. Lastly, participants were asked to fill in the Acceptance Scale (Van der Laan et al., 1997) with regard to the BLCS as a complete system. 


\subsubsection{Data scoring and analyses}

During Task 1, two videos were recorded from the participant's bicycle. With the first video, the camera's perspective was captured to generate and calibrate a perspective grid in Kinovea ${ }^{\mathrm{TM}}$ (Charmant, 2016). In the second video, this grid was used to measure the distances between the rear wheel of the BLCS-bicycle and the front wheel of the participant's bicycle during the experimental rides (i.e., the following-distance). Seven measurements were sampled on fixed locations during each scenario (i.e., seven lampposts, each 24 metres apart). The mean and standard deviation of the followingdistances were calculated with Microsoft ${ }^{\mathrm{TM}}$ Excel $^{\mathrm{TM}}$ and the effects of the BLCS on mental effort were tested with a Wilcoxon signed-rank test for non-normally distributed data. To investigate riding speed estimation accuracy with the support of a BLCS, the differences between the estimated and true riding speeds in Task 2 were calculated and $\Delta$-values were compared between the 'ON' and 'OFF' conditions for each scenario. As the data were non-normally distributed, a Wilcoxon signed-rank test was performed. Lastly, the feedback from the final interviews was audio-recorded and analysed after the experiment. The answers were summarised and specific remarks for all respondents were counted. With regard to the Acceptance Scale (Van der Laan et al., 1997), the median and interquartile ranges were calculated for both subscales and age groups.

\subsubsection{Statistical analyses}

Statistical tests were performed with an $\alpha$-value of 0.05 . Additionally, $r$ effect sizes for non-parametric data were calculated and interpreted: $r \geq .1$ was considered a small effect, $r \geq .3$ a medium effect, and $r \geq .5$ a large effect (Fritz et al., 2012).

\subsection{Study 2}

\subsubsection{Participants}

After Study 1, twelve cyclists $\geq 60$ years were recruited to test a BLCS-bicycle for one week. Participants came from Enschede $(n=5)$ or the province of Groningen $(n=7)$. Their mean age was 68.8 years (S.D. 4.3 ) and $58.3 \%$ was male. In total, $83.3 \%$ lived in an urban and $16.7 \%$ in a rural environment. None of the participants had physical complaints while cycling and all were able to look over their shoulder.

\subsubsection{Materials}

Participants were provided with a BLCS-bicycle similar to the BLCS-bicycle described in paragraph 2.1.2. Seven BLCS-bicycles were available in different forms and sizes, all being conventional (non-electric) bicycles. Participants could choose a bicycle that was most similar to their own. Subjective opinions regarding usability, visibility, safety, effects on cycling behaviour, balance, and intention to use a BLCS in the future were gathered by means of a structured interview. The evaluation mainly focussed on the turning indicator because this was the only component a participant could operate. 


\subsubsection{Procedure}

A BLCS-bicycle was brought to the participant's home by a researcher and instructions about operation and functions were provided. Participants were instructed to cycle as they normally would and that they were not obliged to use the turning indicator, or the BLCS in its entirety, if they did not feel comfortable with it (anymore). Hereafter, the participants gave written informed consent. After a week, the researcher returned to collect the BLCS-bicycle and conducted the interview.

\section{Results}

\subsection{Study 1}

\subsubsection{Task 1: Following-distance and mental effort}

For Task 1, the following-distance measurements of three participants were removed from the analyses due to failed video recordings. Furthermore, the 'decelerating' condition of one participant was discarded because the view was obstructed by another cyclist. The analyses revealed no significant effects of the BLCS on mean followingdistance for each group or scenario (Figure 6). Furthermore, participants rated the amount of mental effort required to estimate the speed of the test leader to follow him or her comfortably (see Table 3). A medium and significant effect was found between the ' $\mathrm{ON}$ ' and 'OFF' conditions in the overall participant group: participants experienced less mental effort while estimating the speed of the lead cyclist with the BLCS enabled. No significant effects were found within the age groups.

Figure 6 The mean following-distance for the conditions BLCS on and off, per scenario slow, accelerating, fast, and decelerating

Mean following-distance (m)

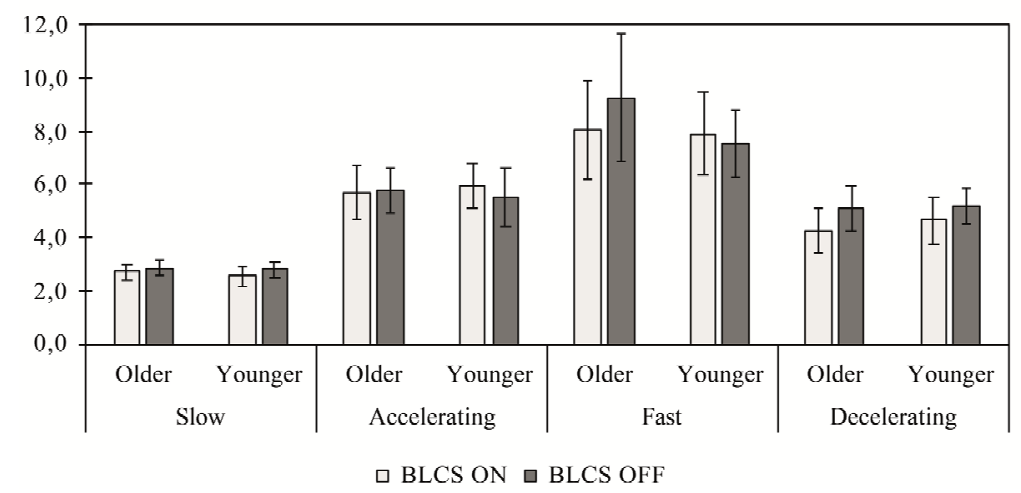

Note: The error bars represent the standard error of the mean (S.E). 
Table 3 Overview of the results from the rating scale mental effort, median and interquartile range (ranging from 0 to 150 )

\begin{tabular}{lccc}
\hline Group & All (median, IQR) & Young (median, IQR) & Old (median, IQR) \\
\hline BLCS 'On' & $26(12.75-48)$ & $33(15-51)$ & $22(11.5-47.5)$ \\
BLCS 'Off' & $32.5(22-63.75)$ & $44(26-76)$ & $29(22-50)$ \\
Z & -2.20 & -1.54 & -1.53 \\
$\mathrm{p}$ & 0.03 & 0.12 & 0.13 \\
$\mathrm{r}$ & 0.35 & 0.35 & 0.33 \\
\hline
\end{tabular}

Source: RSME; Zijlstra (1993)

\subsubsection{Task 2: Riding speed estimations}

The riding speed estimations of one (older) participant were discarded because this participant only gave one estimation in one scenario and felt unable to judge the other scenarios. On average, the slow speed $(12 \mathrm{~km} / \mathrm{h})$ was overestimated $\left(\mathrm{M}_{\mathrm{ON}}=12.5 \pm 3.2 ; \mathrm{M}_{\mathrm{OFF}}=12.9 \pm 3.8\right)$, the medium speed $(17.5 \mathrm{~km} / \mathrm{h})$ was underestimated $\left(\mathrm{M}_{\mathrm{ON}}=14.8 \pm 3.8 ; \mathrm{M}_{\mathrm{OFF}}=15.1 \pm 3.1\right)$, and the high speed $(21 \mathrm{~km} / \mathrm{h})$ was also underestimated $\left(\mathrm{M}_{\mathrm{ON}}=17.9 \pm 4.1 ; \mathrm{M}_{\mathrm{OFF}}=17.5 \pm 3.5\right)$. Comparisons of the $\Delta$-values between the 'ON' and 'OFF' conditions revealed no significant differences in any of the scenarios (see Table 4).

Table 4 The median, interquartile ranges, and Wilcoxon signed rank test results for the effects of the BLCS-system on the deviation between the actual and estimated speed of an approaching cyclist in the slow, medium, and fast speed conditions

\begin{tabular}{lccc}
\hline Condition & Slow & Medium & Fast \\
\hline -values & Median (IQR) & Median (IQR) & Median (IQR) \\
\hline BLCS 'ON' & $2(1-3.875)$ & $2.5(1.5-5.25)$ & $4(2-6)$ \\
BLCS 'OFF' & $2(2-4)$ & $2.5(1.5-4.5)$ & $3.75(2-6)$ \\
$\mathrm{Z}$ & -1.83 & -1.02 & -0.69 \\
$\mathrm{p}$ & 0.07 & 0.31 & 0.49 \\
$\mathrm{r}$ & 0.29 & 0.16 & 0.11 \\
\hline
\end{tabular}

\subsubsection{Subjective evaluations}

Due to failure of the recording equipment, the interviews of three older participants could not be processed. Analyses were therefore based on 38 participants. The majority reported that the overall visibility of the BLCS was good (see Figure 7). Even though the brake light appears to be the least visible, the majority still believed this was good.

Content-wise, none of the participants evaluated the full BLCS-system negatively (Figure 8). Half of all (positive) participants, however, indicated a clear preference for one or more components. Indeed, $37 \%(n=14)$ suggested removing the speed indicator and $13 \%(n=5)$ preferred the turning indicator only. This is also reflected in the evaluations of the individual components: the turning indicator received most positive evaluations, followed by the brake light, while the speed indicator received most negative feedback (see Figure 8). Firstly, the turning indicator was praised for being an 'attention 
grabber', safer on roundabouts, easily seen in the dark, very intuitive, and an opportunity for keeping both hands on the handlebars. Negative comments include believing that people have to get used to it, that some might not use it, or forget to use it. Secondly, even though half of the participants reported not having seen the brake light properly, a small majority was nevertheless positive about this component. Reasons for this were that the brake light attracts attention and provides an extra warning-signal. Contrary opinions suggested that it requires too much focus and was not clearly visible. Thirdly, most participants evaluated the speed indicator negatively because it was not sufficiently visible or understandable. Specifically, the differences between the signals seemed too small to distinguish different speeds and there was a perceived discrepancy between the true riding speed and the displayed BLCS-signals (e.g., the cyclist was expected to ride faster when the ring was half-way lit). Furthermore, for interpretation a vast amount of attention was required, it was considered to be distracting, and not intuitive. Some participants mentioned using other cues for estimating the speed of the BLCS-bicycle rider, such as the movement speed of the legs and pedals. Positive comments revealed that the speed indicator might be helpful for estimating the speed of electric bicycle riders, as some believe that they not only ride faster than conventional cyclists, but also faster than expected based on their pedal movement speed. Potential usefulness in low light conditions was also mentioned.

Figure 7 Participants' opinions (in percentages) about the visibility of BLCS components

\section{Visibility of BLCS Components}

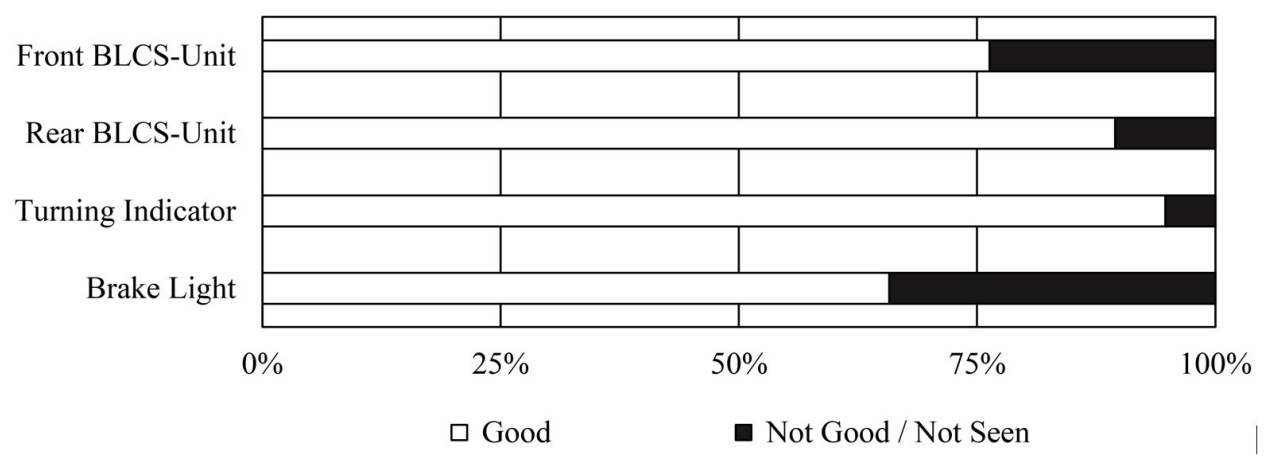

In total, $63 \%(n=24)$ of all participants mentioned that they would like to use a BLCS for themselves and $87 \%(n=33)$ would like others to use it. Furthermore, $87 \%(n=33)$ believes that a BLCS could increase traffic safety, at times added with the remark that everybody should use it and that it is expected to require habituation. With regard to acceptance, all participants were positive about the BLCS in terms of usefulness and satisfaction (Table 5). In addition, older cyclists expected the BLCS to be more useful and satisfying than younger cyclists. 
Figure 8 Participants' opinions (in percentages) about the BLCS-system as a whole and its individual components

\section{Opinion about BICSS and Components}

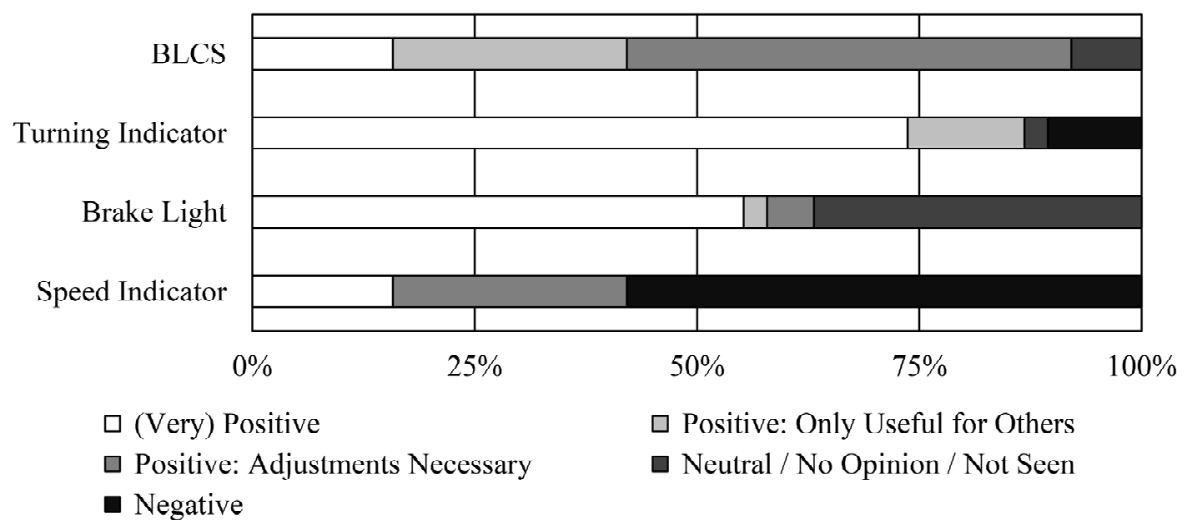

Table 5 Median and interquartile ranges (IQR) for the acceptance subscales (usefulness and satisfaction; scale range -2 to +2 ) and the results of the Wilcoxon ranked test for both age groups

\begin{tabular}{lcc}
\hline Group & Usefulness (median, IQR) & Satisfying (median, IQR) \\
\hline Young & $1(0.8-1.6)$ & $0.75(0.5-1.5)$ \\
Old & $1.8(1.3-2.0)$ & $1.5(1.125-2.0)$ \\
$\mathrm{Z}$ & -2.75 & -2.88 \\
$\mathrm{p}$ & 0.006 & 0.004 \\
$\mathrm{r}$ & 0.43 & 0.46 \\
\hline
\end{tabular}

Source: Van der Laan et al. (1997)

\subsection{Study 2}

\subsubsection{First user-impressions}

After using a BLCS-bicycle for one week, all participants $(n=12)$ mentioned that they used the BLCS turning indicator (nearly) always. One third $(n=4)$ also signalled with one arm if they were unsure that other road users saw the signals or because it was their routine, and $8 \%(n=1)$ kept extending the arm in all situations. A majority $(83 \% ; n=10)$ believed that the turning indicator was clearly visible and that other road users could estimate their intentions correctly.

Regarding balance, $58 \%(n=7)$ mentioned that using the turning indicator did not influence their balance. Furthermore, half of the participants $(n=6)$ felt safer while signalling with the turning indicator. One participant (8\%), however, felt unsafe because the turning indicator took too much effort and required habituation. Remarks stating that the turning indicator was mainly useful while cycling in the dark were given by $42 \%$ $(n=5)$. Nine participants $(75 \%)$ would like to have the turning indicator on their own bicycle, although two of them (17\%) would only like this after experiencing problems 
with extending their arm. However, 25\% $(n=3)$ mentioned that they might feel overconfident while using the turning indicator because people will see me anyway.

Technical feedback mostly concerned the remote-controller. Half of the participants $(n=6)$ stated that the turning indicator was easy to operate although wearing gloves, a rain poncho, or cycling over uneven surfaces could cause difficulties. Also, $50 \%(n=6)$ suggested a different controller (e.g., separate controllers on the left and right-hand sides of the handlebars).

\section{Discussion}

The primary aim of this study was to evaluate the potential of a BLCS to explicitly show cyclists' turning intentions and riding speed to other road users. In Study 1, 21 older and 20 younger cyclists performed two tasks: following and estimating the speed of the test leader on a BLCS-bicycle, followed by an interview to gather subjective evaluations. In Study 2, twelve older cyclists used a BLCS-bicycle for one week to explore their first user-impressions.

\subsection{Main findings}

The first analyses revealed that older and younger cyclists maintain similar followingdistances from a lead cyclist, regardless of presenting a BLCS. Cyclists neither kept more distance from a BLCS-bicycle, nor did they approach it more closely than a conventional bicycle, which means that even though the visibility of the BLCS-signals was sufficient from a 'normal' following-distance, it did not increase safety margins. However, the BLCS-signals were evaluated as less mentally demanding for estimating the riding speed of a lead cyclist, compared to observing the same cyclist on a conventional bicycle. This could mean that the BLCS-signals did contribute to some degree with the task of perceiving (subtle) relative speed changes of a lead cyclist (i.e., accelerating or slowing down compared to an earlier speed). This finding could be important, because a decrease in mental workload is particularly beneficial in situations where it is difficult to gain an overview, for example at intersections (Dozza and Werneke, 2014; Westerhuis et al., 2016). Such situations are, however, not limited to cycling behind other cyclists, and the second analyses revealed that the BLCS-signals did not assist participants with correctly estimating the riding speed of approaching cyclists from larger distances. Indeed, many participants reported that they perceived a discrepancy between the observed speeds of the approaching cyclist and the displayed BLCS-signals: these were not clear or intuitive, explaining many of the negative subjective evaluations. Although some mentioned that BLCS speed information might be useful in faded lighting conditions, these findings indicate that the presented BLCS-signals displaying riding speed did not provide sufficient additional value compared to solely observing rider behaviour.

Despite the speed-signal, the BLCS was evaluated as a useful and satisfying device mainly because of other components. Indeed, positive to very positive ratings were given about the brake light and the turning indicator, implying that these could be valuable features for (older) cyclists. Particular qualities such as intuitiveness and quickly attracting the attention of other road users seem useful and desired, and the brake light may therefore be a functional warning signal that a cyclist is decelerating without knowing the specific speed at that time. Furthermore, the first user-impressions showed 
that the turning indicator was used by most participants and even though the majority did not report improvements in keeping balance, many would like to use it on their own bicycles. It should be kept in mind, however, that in Study 1, relatively more participants mentioned that they would like others to use a BLCS compared to using a BLCS for themselves. Because the purpose of the light signals that are displayed by the BLCS is to communicate a cyclist's own behaviour and intentions to other road users, this could suggest that relatively more cyclists are interested in receiving BLCS-signals from other cyclists than sending such signals towards other road users. This may indicate that the signals that were evaluated positively (i.e., the direction indicator and the brake light) provide valuable information to use while cycling. It could also be, however, that part of the cyclists feel they do not need a BLCS on their bicycles and that other cyclists may need it more. In addition, none of the participants of Study 2 mentioned that they suffered from balance problems. Taken together, the BLCS seems to meet only few of the wishes: it provides support with indicating direction and explicitly shows braking behaviour to other road users. However, it does not seem to support the estimation of the constant cruising speed of a cyclist, or more subtle speed changes that do not require braking, particularly when perceived from larger distances.

It should be noted that in Study 1, many participants mentioned that it was generally difficult to estimate riding speeds with certainty, regardless of providing BLCS-signals. Because only riding speeds and the availability of BLCS-signals differed between scenarios and conditions, it seems likely that other cues are more distinctive or relied upon. Firstly, there were no other vehicles around to compare speed with or estimate inbetween gaps. Secondly, as the researchers made sure that cadence was similar in all scenarios, it might be that differentiating riding speeds was too difficult with this specific cue made unavailable. Indeed, in line with the findings of Schleinitz et al. (2016) and Haustein and Møller (2016), it seems that cadence, or perceived effort investment, is also used for estimating riding speed. Even though this could mean that the experimental manipulation was successful (i.e., keeping cadence constant in all scenarios), this also confirms that the BLCS did not provide usable information instead. However, because cadence is also not a sufficiently reliable cue for estimating riding speed (Dozza et al., 2016; Petzoldt et al., 2017), it may still be beneficial to develop alternative cues or signals to counteract riding speed misjudgements. Based on earlier research, it could be that larger bicycle light units may be more successful because these could enlarge the possibilities for perceiving changes in visual angle and/or visual space between individual lights (Parker et al., 1964, cited in Moore and Rumar, 1999). Even though a bicycle is a relatively narrow vehicle, perhaps vertically instead of horizontally separated lights could be used to enhance distance and speed perception.

\subsection{Limitations}

The present research has some limitations. Firstly, the BLCS was a prototype and prototypes do not always work perfectly. For example, the brake light was not activated by enabling the brakes but only when the BLCS-bicycle was decelerating beyond a threshold. It could therefore be that the system was not yet triggered to show the brake light even if the test leader was braking, which might have influenced followingbehaviour and visibility ratings. Secondly, the researchers tried to simulate a realistic traffic environment while performing a controlled experiment. This setting could have made participants more focussed than in a non-research setting, also because they did not 
have to react or make a manoeuvre. Specifically, in Task 2 participants stood still and could pay full attention to the approaching BLCS-cyclist. Real traffic situations, however, tend to be denser, more crowded, and require riding and monitoring simultaneously, making it more difficult to focus on one signal. Thirdly, participants might have been able to guess the goal of the study and acted in a way that they believed the researchers would have liked. For this reason, the conditions and scenarios in Study 1 (i.e., Task 1 and Task 2) were presented in a balanced and randomised order. As the interviews in Study 1 and Study 2 mainly concerned personal opinions of participants, however, it cannot be ruled out that some bias may have occurred. Fourthly, Study 1 was only performed in stable weather with clear visibility conditions although in real life, these conditions differ. For example, evaluation could be different in faded light conditions because lights become more visible while other cues become less visible, which was also mentioned by several participants. Favourable visibility conditions were preferred because particularly older cyclists mainly cycle during the day and in pleasant weather conditions (Engbers et al., 2018a). Fifthly, the used BLCS-bicycles were all conventional bicycles even though misinterpretations of riding speeds seem to occur mainly with electric bicycles. Nevertheless, conventional bicycles were used because of availability reasons and their usability for demonstrating lower speed scenarios. Furthermore, effects of bicycle type on signal perception should be limited, because modern electric bicycles look similar to conventional bicycles (Dozza et al., 2016). Lastly, the researchers asked the participants in Study 1 with an electric bicycle to disable their electric support if possible. Even though none of these participants had any problems with this, in hindsight, this may have affected their cycling behaviour, particularly at low speeds.

Even though Study 1 was performed near a city and on a well-reachable location, the majority of older participants may have been relatively fit compared to the 'average' older cyclist. Because Study 1 mainly concerned perception, it is expected that the influence of physical fitness on the results of that study is limited. However, also because the sample of Study 2 was partly drawn from Study 1, it could be that the relative fitness of older participants influenced the results of Study 2. Particularly regarding balance, it may have been more informative to include cyclists with balance difficulties. For ethical and safety reasons, however, it was not possible to request people with profound difficulties to test a first prototype BLCS-bicycle in real traffic. Because Study 2 suggests that indicating direction with a BLCS does not influence balance (i.e., no increase, but also no decrease in balance), a next step might be to study a BLCS with cyclists who are afraid to lose balance or struggle with looking over their shoulder.

Future research could also focus on the consequences of using (components of) a BLCS in daily life. For example, it is unknown how other road users (e.g., car drivers or pedestrians) respond to such signals from a bicycle. Furthermore, it should be noted that safety effects might also be negative in real traffic. For example, if many BLCS-bicycles simultaneously convey numerous signals, these might lead to visual clutter and cognitive overload, which should be prevented.

\subsection{Conclusions and implications for practice}

Dedicated light signals showing a cyclist's turning intentions and braking behaviour are appreciated by (older) cyclists, both for use on their own bicycles and for use by other cyclists, even though no effects on cycling behaviour or the accuracy of estimating constant cruising speeds were found. A turning indicator may have a positive effect on 
balance of older cyclists because the number of arm movements can be reduced and replaced by pushing a button to enable the signal. Brake lights and turning indicators could therefore have added value for cyclists, because other road users should be well able to interpret the turn and brake signals because these are already obligatory and known as effective on other vehicle types, including mopeds and motorcycles (Moore and Rumar, 1999; Sullivan and Flannagan, 2012). In addition, blinking signals are detected easier than stationary signals (Cohen, 1987, cited in Faw, 2013) and a modelling effect might occur as other road users are reminded to indicate direction as well (Faw, 2013). Currently, however, not all countries allow the use of 'blinking' lights on a bicycle. An example of these countries are the Netherlands (Rijksoverheid, n.d.). As this may hinder further development and maturation of light signalling systems for cyclists, it could be helpful if legal boundaries for bicycle lights are expanded to not only include 'regular' front and rear bicycle lights, but also possibilities for implementing (blinking) light signals for communication purposes.

With regard to reliably estimating constant riding speed, this remains difficult regardless of the presented BLCS-signals. It may, however, still be beneficial to explore alternative options to counteract speed misjudgements. For example, multiple lights might be used vertically to enable estimating speed and distance by perceiving the angular size or physical separation between lights or light-elements (Moore and Rumar, 1999).

\section{Acknowledgements}

The authors would like to thank Ivar Koehorst, Marianne Meijerink, and Maurice Tak of Indes for developing the BLCS and providing valuable assistance during the study. Furthermore, the authors would also like to thank Niek Kamphuis and Jaap Buurke for their assistance with preparing the study. This work was part of the CRUISer project that was supported by ZonMW SPRINT, Innovative Medical Devices Initiative 2014 (Project code 104003007).

\section{Contribution}

Frank Westerhuis and Carola Engbers contributed equally.

\section{References}

Bernhoft, I.M. and Carstensen, G. (2008) 'Preferences and behaviour of pedestrians and cyclists by age and gender', Transportation Research Part F, Vol. 11, No. 2, pp.83-95, DOI: 10.1016/j.trf.2007.08.004

Boele-Vos, M., Van Duijvenvoorde, K., Doumen, M., Duivenvoorden, C., Louwerse, W. and Davidse, R. (2017) 'Crashes involving cyclists aged 50 and over in the Netherlands: an indepth study', Accident Analysis and Prevention, Vol. 105, pp.4-10, DOI: 10.1016/j.aap.2016.07.016

Bulsink, V.E., Kiewiet, H., Van de Belt, D., Bonnema, M. and Koopman, B. (2016) 'Cycling strategies of young and older cyclists', Human Movement Science, Vol. 46, pp.184-195, DOI: 10.1016/j.humov.2016.01.005 
Charmant, J. (2016) Kinovea (Version 0.8.25) Computer Software [online] https://www.kinovea.org (accessed 21 June 2017)

Cohen, A.S. (1987) 'The latency of simple reaction on highways: a field study', Public Health Rev., Vol.15, No. 4, pp.291-310.

Davidse, R., Van Duijvenvoorde, K., Boele, M., Doumen, M., Duivenvoorden, C. and Louwerse, W. (2014a) Fietsongevallen van 50-plussers: Karakteristieken en Ongevalsscenario's van Enkelvoudige Ongevallen en Botsingen met Overig Langzaam Verkeer (Bicycle crashes of Cyclists aged 50+ years: Characteristics and crash Scenarios of Single-Bicycle Crashes and Collisions with other Slow Traffic) SWOV Institute for Road Safety Research, The Hague.

Davidse, R., Van Duijvenvoorde, K., Boele, M., Duivenvoorden, C. and Louwerse, W. (2014b) Fietsongevallen Met 50-Plussers in Zeeland: Hoe Ontstaan ze en Welke Mogelijkheden zijn er om ze te Voorkomen? (Bicycle Crashes of Cyclists Aged 50+ years in Zeeland: What Causes these and which Possibilities are there to Prevent them?) SWOV Institute for Road Safety Research, The Hague.

De Hartog, J.J., Boogaard, J., Nijland, H. and Hoek, G. (2010) 'Do the health benefits of cycling outweigh the risks?', Environmental Health Perspectives, Vol. 118, No. 8, pp.1109-1116, DOI: $10.1289 /$ ehp.0901747

Dozza, M. and Werneke, J. (2014) 'Introducing naturalistic cycling data: What factors influence bicyclists' safety in the real world?', Transportation Research Part F, Vol. 24, pp.83-91, DOI: $10.1016 /$ j.trf.2014.04.001

Dozza, M., Piccinini, G.F. and Werneke, J. (2016) 'Using naturalistic data to assess e-cyclist behavior', Transportation Research Part F, Vol. 41, pp.217-226, DOI: 10.1016/j.trf.2015.04.003

Dubbeldam, R., Baten, C., Buurke, J.H. and Rietman, J.S. (2017a) 'SOFIE, a bicycle that supports older cyclists?', Accident Analysis and Prevention, Vol. 105, pp.117-123, DOI: 10.1016/j.aap.2016.09.006

Dubbeldam, R., Baten, C.T.M., Straathof, P.T.C., Buurke, J.H. and Rietman, J.S. (2017b) 'The different ways to get on and off a bicycle for young and old', Safety Science, Vol. 92, pp.318329, DOI: 10.1016/j.ssci.2016.01.010

Engbers, C., Dubbeldam, R., Brusse-Keizer, M.G.J., Buurke, J.H., De Waard, D. and Rietman, J.S. (2018a) 'Characteristics of older cyclists $(65+)$ and factors associated with self-reported cycling accidents in the Netherlands', Transportation Research Part F, Vol. 56, pp.522-530, DOI: $10.1016 /$ j.trf.2018.05.020

Engbers, C., Dubbeldam, R., Buurke, J.H., Kamphuis, N., de Hair-Buijssen, S.H.H.M., Westerhuis, F., De Waard, D. and Rietman, J.S. (2018b) 'A front- and rear-view assistant for older cyclists: evaluations on technical performance, user experience and behaviour', International Journal of Human Factors and Ergonomics, Vol. 5, No. 4, pp.257-276, DOI: 10.1504/IJHFE.2018.096099

Engbers, C., Dubbeldam, R., Buurke, J.H., Schaake, L., De Goede, M., Rietman, J.S. and De Waard, D. (2016) 'The acceptance of a prototype rear-view assistant for older cyclists: two modalities of warnings compared', International Journal of Human Factors and Ergonomics, Vol. 4, pp.264-281, DOI: 10.1504/IJHFE.2016.083520

Faw, H.W. (2013) 'To signal or not to signal: That should not be the question', Accident Analysis and Prevention, Vol. 59, pp.374-381, DOI: 10.1016/j.aap.2013.06.036

Fishman, E., Schepers, P. and Kamphuis, C.B. (2015) 'Dutch cycling: quantifying the health and related economic benefits', American Journal of Public Health, Vol. 105, No. 8, pp.e13-e15, DOI: 10.2105/AJPH.2015.302724

Fritz, C. O., Morris, P. E. and Richler, J. J. (2012) 'Effect size estimates: current use, calculations, and interpretation', Journal of Experimental Psychology, Vol. 141, No. 1, pp.2-18, DOI: $10.1037 / \mathrm{a} 0024338$

Green, M. (2000) 'How Long Does It Take to Stop? Methodological analysis of driver perceptionbrake times', Transportation Human Factors, Vol. 2, No. 3, pp.195-216. 
Hagemeister, C. and Tegen-Klebingat, A. (2012) 'Cycling habits and accident risk of older cyclists in Germany' in Proceedings of the International Cycling Safety Conference, Helmond, The Netherlands.

Harms, L. and Kansen, M. (2018) Cycling Facts, Netherlands Institute for Transport Policy Analysis (KiM) The Hague [online] https://english.kimnet.nl/binaries/kimnetenglish/documents/publications/2018/04/06/cycling-facts/cycling+facts_PDF+a.pdf (accessed 22 January 2019).

Haustein, S. and Møller, M. (2016) 'E-bike safety: Individual-level factors and incident characteristics', Journal of Transport \& Health, Vol. 3, pp.386-394, DOI: 10.1016/j.jth.2016.07.001

Hemeren, P.E., Johannesson, M., Lebram, M., Eriksson, F., Ekman, K. and Veto, P. (2014) 'The use of visual cues to determine the intent of cyclists in traffic', in IEEE International InterDisciplinary Conference on Cognitive Methods in Situation Awareness and Decision Support (CogSIMA), pp.47-51, DOI: 10.1109/CogSIMA.2014.6816539

Johnsen, A. and Funk, W. (2019) 'Requirements for Assisting Senior Cyclists - An Integrative Approach', in Lightner, N.J. (Ed.): Advances in Intelligent Systems and Computing: Proceedings of the AHFE 2018 International Conference on Human Factors and Ergonomics in Healthcare and Medical Devices, July 21-25, 2018, Loews Sapphire Falls Resort Universal Studios, Orlando, Florida, USA (Vol. 779, pp. 297-307) Springer International Publishing AG, DOI: 10.1007/978-3-319-94373-2_33

Johnson, M. and Rose, G. (2015) 'Extending life on the bike: electric bike use by older Australians', Journal of Transport \& Health, Vol. 2, pp.276-283, DOI: 10.1016/j.jth.2015.03.001

Kahane, C.J. and Hertz, E. (1998) 'The long-term effectiveness of center high mounted stop lamps in passenger cars and trucks (Report, No. DOT HS 808 696), National Highway Traffic Safety Administration, Washington DC.

Kennisinstituut voor Mobiliteitsbeleid (2017) Mobiliteitsbeeld 2017 (Mobility Image 2017), Ministry of Infrastructure and Environment, The Hague [online] https://www.kimnet.nl/ binaries/kimnet/documenten/rapporten/2017/10/23/mobiliteitsbeeld2017/mobiliteitsbeeld_2017.pdf (accessed 3 June 2019)

Kooiman, J., Meijaard, J., Papadopoulos, J. M., Ruina, A. and Schwab, A. (2011) 'A bicycle can be self-stable without gyroscopic or caster effects', Science, Vol. 6027, pp.339-342, DOI: 10.1126/science.1201959.

Kruijer, H., Den Hartog, P., Klein Wolt, K., Panneman, M. and Sprik, E. (2012) Fietsongevallen in Nederland (Bicycle Accidents in The Netherlands) VeiligheidNL, Amsterdam.

Kulmala, R. and Rämä, P. (2013) 'Definition of Behavioural Adaptation', In C. M. Rudin-Brown, and S. L. Jamson, Behavioural Adaptation and Road Safety: Theory, Evidence and Action (pp.11-22) Boca Raton, FL: CRC Press; Taylor \& Francis Group.

Ministry of Transport, Public Works, and Water Management (2008) Strategisch plan verkeersveiligheid 2008-2020: Van voor en door iedereen (Strategical plan traffic safety 20082020: for and by everbody) [online]. Ministry of Transport, Public Works and Water Management, The Hague [online] https://www.rijksoverheid.nl/binaries/rijksoverheid/ documenten/beleidsnota-s/2008/07/10/strategisch-plan-verkeersveiligheid-2008-2020-vanvoor-en-door-iedereen/strategisch-plan-verkeersveiligheid-2008-2020.pdf (accessed 23 October 2015)

Moore, D.W. and Rumar, M. (1999) Historical Development and Current Effectiveness of Rear Lighting Systems (Report, No. UMTRI-99-31), The University of Michigan Transportation Research Institute, Ann Arbor, MI.

Muhrer, E. and Vollrath, M. (2010) 'Expectations while car following-The consequences for driving behaviour in a simulated driving task', Accident Analysis and Prevention, Vol. 42, No. 6, pp.2158-2164, DOI: 10.1016/j.aap.2010.07.009

Näätänen, R. and Summala, H. (1976) Road-User Behaviour and Traffic Accidents, NorthHolland/American Elsevier, Amsterdam and New York. 
OECD (2001) Ageing and Transport: Mobility Needs and Safety Issues, OECD Publications, Paris, DOI: $10.1787 / 9789264195851$-en

Oja, P., Titze, S., Bauman, A., de Geus, B., Krenn, P., Reger-Nash, B. and Kohlberger, T. (2011) 'Health benefits of cycling: a systematic review', Scandinavian Journal of Medicine \& Science in Sports, Vol. 21, pp.496-509, DOI: 10.1111/j.1600-0838.2011. 01299.x.

Ormel, W., Klein Wolt, K. and Den Hertog, P. (2008) Enkelvoudige fietsongevallen: Een LISvervolgonderzoek, Rijkswaterstaat Dienst Verkeer en Scheepvaart (RWS DVS).

Parker, J.F., Gilbert, R.R. and Dillon, R.F. (1964) Effectiveness of Three Visual Cues in the Detection of Rate of Closure at Night, Report, No. 64-1, BioTechnology Inc., Arlington, VA.

Petzoldt, T., Schleinitz, K., Gehlert, T. and Krems, J. F. (2017a) 'Drivers' gap acceptance in front of approaching bicycles - Effects of bicycle speed and bicycle type', Safety Science, Vol. 92, pp.283-289, DOI: 10.1016/j.ssci.2015.07.021

Petzoldt, T., Schleinitz, K., Heilmann, S. and Gehlert, T. (2017b) 'Traffic conflicts and their contextual factors when riding conventional vs. electric bicycles', Transportation Research Part F, Vol. 46, pp.477-490, DOI: 10.1016/j.trf.2016.06.010

Rijksoverheid (n.d.) Wat zijn de Regels Voor Fietsverlichting en Reflectie Op een Fiets (What are the regulations for bicycle lighting and reflection on a bicycle) [online] https://www.rijksoverheid.nl/onderwerpen/fiets/vraag-en-antwoord/wat-zijn-de-regels-voorfietsverlichting-en-reflectie-op-een-fiets

Rijkswaterstaat (2016) Verkeersveiligheid Ouderen: Interventies Voor Beperking Van Verkeersrisico's Bij Ouderen Anno 2015 (Traffic Safety of the Elderly: Interventions to Limit Traffic Risks of the Elderly in the Year 2015) [online] https://www.rijksoverheid.nl/binaries/ rijksoverheid/documenten/rapporten/2016/05/25/verkeersveiligheid-ouderen/notitieverkeersveiligheid-ouderen-definitief.pdf (accessed 8 December 2016).

Ryan, J., Svensson, H., Rosenkvist, J., Schmidt, S. and Wretstrand, A. (2016) 'Cycling and cycling cessation in later life: findings from the city of Malmö', Journal of Transport \& Health, Vol. 3, No. 1, pp.38-47, DOI: 10.1016/j.jth.2016.01.002

Sacchetti, M., Lenti, M., Di Palumbo, A.S. and De Vito, G. (2010) 'Different effect of cadence on cycling efficiency between young and older cyclists', Medicine \& Science in Sports \& Exercise, Vol. 42, No. 11, pp.2128-2133.

Scheiman, S., Moghaddas, H. S., Björnstig, U., Bylund, P. O. and Saveman, B. I. (2010) 'Bicycle injury events among older adults in Northern Sweden: a 10-year population-based study', Accident Analysis and Prevention, Vol. 42, No. 2, pp.758-763, DOI: 10.1016/j.aap.2009 .11 .005 .

Schepers, P. (2013) A Safer Road Environment for Cyclists, PhD thesis, Stichting Wetenschappelijk Onderzoek Verkeersveiligheid, Leidschendam, The Netherlands.

Schepers, P., Agerholm, N., Amoros, E., Benington, R., Bjørnskau, T., Dhondt, S., De Geus, B., Hagemeister, C., Loo, B.P.Y. and Niska, A. (2015) 'An international review of the frequency of single-bicycle crashes (SBCs) and their relation to bicycle modal share', Injury Prevention, Vol. 21, pp.138-143, DOI: 10.1136/injuryprev-2013-040964

Schepers, P., Fishman, E., Den Hertog, P., Klein Wolt, K. and Schwab, A. (2014) 'The safety of electrically assisted bicycles compared to classic bicycles', Accident Analysis and Prevention, Vol. 73, pp.174-180, DOI: 10.1016/j.aap.2014.09.010.

Schepers, P., Stipdonk, H., Methorst, R. and Olivier, J. (2017) 'Bicycle fatalities: Trends in crashes with and without motor vehicles in The Netherlands', Transportation Research Part F, Vol. 46, pp.491-499, DOI: 10.1016/j.trf.2016.05.007

Schleinitz, K., Petzoldt, T., Franke-Bartholdt, L., Krems, J.F. and Gehlert, T. (2017) 'The German naturalistic cycling study - comparing cycling speed of riders of different e-bikes and conventional bicycles', Safety Science, Vol. 92, pp.290-297, DOI: 10.1016/j.ssci.2015.07.027. 
Schleinitz, K., Petzoldt, T., Krems, J.F. and Gehlert, T. (2016) 'The influence of speed, cyclists' age, pedaling frequency, and observerage on observers' time to arrival judgments of approaching bicycles and e-bikes', Accident Analysis and Prevention, Vol. 92, pp.113-121, DOI: 10.1016/j.aap.2016.03.020.

Sullivan, J.M. and Flannagan, M.J. (2012) 'The influence of rear turn-signal characteristics on crash risk', Journal of Safety Research, Vol.43, pp.59-65, DOI: 10.1016/j.jsr.2011.12.003.

SWOV (2013) 'SWOV-Factsheet Oudere fietsers', SWOV, Leidschendam [online] https://www.swov.nl/file/13371/download?token=Kd-_BV7O (accessed 3 December 2018).

Theurel, J., Theurel, A. and Lepers, R. (2012) 'Physiological and cognitive responses when riding an electrically assisted bicycle versus a classical bicycle', Ergonomics, Vol. 55, No. 7, pp.773-781, DOI: 10.1080/00140139.2012.671964.

Tour de Force (2017) Bicycle Agenda 2017-2020 [online] http://tourdeforce2020.nl/wpcontent/uploads/2017/02/Bicycle_Agenda_2017-2020.pdf (accessed 14 December 2018).

Twisk, D., Platteel, S. and Lovegrove, G. (2017) 'An experiment on rider stability while mounting: comparing middle-aged and elderly cyclists on pedelecs and conventional bicycles', Accident Analysis and Prevention, Vol. 105, pp.109-116, DOI: 10.1016/j.aap.2017.01.004.

Van Cauwenberg, J., Schepers, P., Deforche, B. and De Geus, B. (2019) 'Differences in life space area between older non-cyclists, conventional cyclists and e-bikers', Journal of Transport \& Health, Vol. 14, p.100605, DOI: 10.1016/j.jth.2019.100605.

Van der Laan, J.D., Heino, A. and De Waard, D. (1997) 'A simple procedure for the assessment of acceptance of advanced transport telematics', Transportation Research Part C: Emerging Technologies, Vol. 5, No. 1, pp.1-10, DOI: 10.1016/S0968-090X (96)00025-3.

VeiligheidNL/Rijkswaterstaat (2017) Fietsongevallen in Nederland: SEH-Behandelingen 2016 (Bicycle Crashes in the Netherlands, ER-treatments 2016 VeiligheidNL, Amsterdam [online] https://www.veiligheid.nl/organisatie/actueel/nieuws/rapport-oorzaken-fietsongevallen (accessed 3 December 2018).

Vlakveld, W.P., Twisk, D., Christoph, M., Boele, M., Sikkema, R., Remy, R. and Schwab, A.L. (2015) 'Speed choice and mental workload of elderly cyclists on e-bikes in simple and complex traffic situations: a field experiment', Accident Analysis and Prevention, Vol. 74, pp.97-106, DOI: 10.1016/j.aap.2014.10.018.

Walker, I. (2005) 'Signals are informative but slow down responses when drivers meet bicyclists at road junctions', Accident Analysis and Prevention, Vol. 37, No. 6, pp.1074-1085, DOI: 10.1016/j.aap.2005.06.005.

Wegman, F., Aarts, L. and Bax, C. (2008) 'Advancing sustainable safety: national road safety outlook for The Netherlands for 2005-2020', Safety Science, Vol. 46, pp.323-343.

Westerhuis, F. and De Waard, D. (2016) 'Using commercial GPS action cameras for gathering naturalistic cycling data', Journal of the Society of Instrument and Control Engineers (SICE) of Japan, Vol. 55, No. 5, pp.422-430, DOI: 10.11499/sicej1.55.422.

Westerhuis, F. and De Waard, D. (2017) 'Reading cyclist intentions: can a lead cyclist's behaviour be predicted?', Accident Analysis and Prevention, Vol. 105, pp.146-155, DOI: 10.1016/j.aap.2016.06.026.

Westerhuis, F., Engbers, C., Dubbeldam, R. and De Waard, D. (2016) What do Older Cyclists Experience? An Identification Study of Perceived Difficulties in Everyday Cycling Interactions, SPRINT-CRUISer Project Report.

Zijlstra, F. (1993) Efficiency in Work Behavior: A Design Approach for Modern Tools, PhD thesis, Delft University of Technology, Delft, The Netherlands. 